\title{
Iron Sucrose Injection
}

National Cancer Institute

\section{Source}

National Cancer Institute. Iron Sucrose Injection. NCI Thesaurus. Code C60883.

A sterile aqueous complex of polynuclear iron (III)-hydroxide in sucrose for intravenous use. Following intravenous administration, iron sucrose is dissociated by the reticuloendothelial system into iron and sucrose; the sucrose component is eliminated mainly by urinary excretion. Iron sucrose can be administered with or without erythropoietin to raise hemoglobin levels and may be used in cases of oral iron therapy intolerance or ineffectiveness. Hypersensitivity reactions are less common with iron sucrose compared to other parenteral iron products, such as iron dextran. 